\title{
El clickbait como estrategia del sensacionalismo en Depor.com para informar sobre el caso Paolo Guerrero y su vinculación a Boca Juniors entre noviembre de 2019 y enero de 2020
}

\section{How clickbait is used on Depor.com to inform about the probable transfer of Paolo Guerrero to Boca Juniors between november 2019 and} january 2020

Recibido: 04/11/2020

Aceptado: 06/06/2021

Publicado: 30/06/2021
Héctor Alberto Melgar Sandoval u201213812@upc.edu.pe http://orcid.org/0000-0003-1939-8859

Universidad Peruana de Ciencias Aplicadas (Perú)

Resumen: El presente trabajo de investigación evidencia cómo el diario deportivo peruano web Depor.com utiliza recurrentemente el clickbait, entendido como anzuelo de clic, por su traducción al inglés; como estrategia del sensacionalismo para informar sobre el posible traspaso de Paolo Guerrero a Boca Juniors entre noviembre de 2019 y enero de 2020. Este accionar del diario peruano produce una corriente de desinformación en el ecosistema digital y genera un nuevo lenguaje que tiene como características principales: titulares muy atractivos y exagerados con un desglose o contenido disparejo vinculado a la especulación e interpretación. De esta manera, se crea una normalización del uso del clickbait para informar sobre traspasos o fichajes de jugadores en el fútbol internacional. 
Palabras clave: Clickbait, Sensacionalismo, Desinformación, Fútbol, Paolo Guerrero, Traspaso, Especulación.

Abstract: This research work shows how the Peruvian sports newspaper Depor.com repeatedly uses clickbait. It is understood as click hook, because of its translation into English; as a strategy of sensationalism to report on the possible transfer of Paolo Guerrero to Boca Juniors between November 2019 and January 2020. This action of the Peruvian newspaper produces a current of disinformation in the digital ecosystem and generates a new language that has as main characteristics: Very attractive and exaggerated headlines with uneven breakdown or content linked to speculation and interpretation. In this way of the use of clickbait is created to be able to inform about transfers or signings of players in international football.

Key words: Clickbait, Sensationalism, Disinformation, Soccer, Paolo Guerrero, Transfers, Speculation.

\section{Introducción}

Usuarios en redes sociales, como son Facebook y Twitter, muestran su enojo y realizan comentarios, señalando que el diario Depor.com, en su formato web, es "vende humo". Este concepto, según el Diccionario de la lengua española de la Real Academia Española (RAE), se escribe como "vendehúmos" y lo explica como una "persona que ostenta o simula valimiento o privanza con un poderoso para vender su favor a los pretendientes". En otras palabras, se estaría fingiendo de poseer algo valioso con el solo hecho de ofertar algún material o información. Esta definición aplicada al fútbol se podría enlazar con una nota informativa del diario argentino Clarín (2018), el cual evidencia al entrenador Ricardo Caruso Lombardi como "vende humo", informando así que es una "persona que hace alarde de conocimientos, talentos, experiencias o riquezas que no puede constatar, razón por la cual es alguien al que no se le debe prestar atención o, al menos, no se le debe creer".

A partir de este concepto, podría adaptarse la línea periodística del diario Depor.com a esta explicación, ya que se estaría evidenciando que, según los usuarios, divulgaría información con poca rigurosidad o falta de fuentes fidedignas y, en consecuencia, no sería objetivo en su discurso. El uso de titulares bastantes llamativos como "Sería invencible: el poderoso XI de Boca con 
Paolo Guerrero que iría a por la Copa Libertadores 2020" o "Paolo Guerrero ya tiene fecha de llegada a Boca Juniors y develan cuánto ganará como 'xeneize"" es una estrategia llamativa, pero denota que no se llega a mencionar toda la información, por lo contrario, dejan contenido siempre en incógnita. Esta forma de redacción es motivo también de investigación y, por lo tanto, un problema a solucionar.

Al exponer esta explicación, se traería a colación el concepto de sensacionalismo, pues se estaría demostrando que se hace uso de esta definición a manera global en gran parte de la redacción de noticias de dicho diario nacional. En ese sentido, conforme a Gargurevich (1999), el sensacionalismo es una "magnificación o exageración de las noticias reales" (p.26). En consecuencia, se estaría priorizando lo sensacional de lo serio, este último concepto como una de las características importantes del periodismo. Contrastando esta idea, también se hablaría que el periodismo serio tiene, como obligación, la reflexión del público a raíz de información relevante y de interés colectivo y, por el contrario, la prensa sensacionalista tendría objetivos comerciales y entretener a toda costa (Redondo, 2013).

De otro modo, también se demostraría la desinformación como parte del discurso de Depor.com. Por ello, Flores (2019) explica que este término "no es un contenido falso, o que no es completamente falso, pero que es información fabricada, mezclada con hechos y prácticas que poco tienen que ver con el concepto de noticia" (p.105).

La problemática que se genera a partir de Depor.com es que difundiría información con titulares llamativos, pero con un desglose o contenido relacionado a la especulación. Ante esto, se podría hablar de un evidente panorama de desinformación que conlleva una normalización del clickbait en las diversas notas informativas. Es, por tanto, importante estudiar este fenómeno, pues la estrategia de informar con medias verdades podría conllevar que, por su recurrencia, sea una práctica válida.

\section{La transición del periodismo escrito al digital y su adaptación al Perú}

\subsection{Del periodismo escrito a la adaptación digital}

Acontecimientos sociológicos, revoluciones y diferentes manifestaciones cambiaron la forma de vivir de los ciudadanos y alentaron a que las mino- 
rías puedan expresarse y decir lo que piensan. Estos cambios tuvieron como pieza fundamental a la comunicación y, posteriormente, al derecho a la información, dado que, sin el desarrollo de una opinión pública, la sociedad no hubiera podido ejercer su opinión ni voto. La historia determinó que diversas culturas, como la griega, china, persa, entre otras, tuvieran un sistema para transportar información, que en principio fue oral. Este sistema después se trasladó al material físico, como papiros, pergaminos, tablas de cera y, finalmente al papel (Gargurevich, 1999). Un punto de quiebre en la historia fue el paso de la producción feudal al capitalismo, ya que las dinámicas de comercialización e información se vieron marcadas por nuevos instrumentos como las "nuevas guarniciones para caballerías, la aguja de marear, el timón de codaste, el papel y la imprenta" (Vázquez, 1980, p.31); siendo este último, factor determinante para la información en general. Se conoce que este instrumento, en un primer momento, fue de gran valoración para la literatura, antes que para la prensa.

Se debe recordar que, en el año 1450, Johannes Gutenberg creó la imprenta, la cual permitía la reproducción de libros y publicaciones a gran escala. Anteriormente a esta innovación, solo se utilizaba la xilografía, un método bastante trabajoso y agotador. A este cambio de la historia, también se le denominaría "revolución de la imprenta", que dio pase a la Revolución Francesa y, posteriormente, a la Revolución Industrial (Briggs \& Burke, 2002).

La prensa masiva se inicia con la Revolución Industrial, pues el cambio del modelo artesanal a la industria generó que las fábricas compren máquinas a vapor para acelerar la producción. Las grandes empresas de las principales ciudades del mundo empezaban a manejar grupos de trabajo extensos y se generaban los conceptos de empresario-capitalista y proletariado (Gargurevich, 1999).

\subsection{El Perú se adapta a los medios web}

En el Perú, la historia innovadora era distinta y la prensa masiva aún no llegaba a iniciarse. Los medios que existían se crearon con objetivos partidistas e ideológicos (Hinojosa, 2014). Por ello, un ejemplo: en la época del Virreinato, la burguesía criolla trataba de dar a conocer su postura o punto de vista, que debía tocarse en ese momento. "El Diario de Lima se posicionó como el medio alternativo a las publicaciones españolas" (Hinojosa, 2014, p.275). 
El ecosistema de la prensa en Europa y Estados Unidos era totalmente distinto al de Latinoamérica, especialmente en Perú. En los países del primer mundo ya se estaba introduciendo el concepto de sociedad de la información. Barja (2016) explica que, cuando se habla de esta nueva clase de sociedad, "ha sido nombrado por diversos teóricos a lo largo de los años con vastos términos, entre los que destacan los conceptos de sociedad post-industrial, sociedad red y sociedad digital, a fin de nombrar al mismo fenómeno" (p. 36).

Las palabras clave para este concepto de sociedad son "red" y "digital". La invención de la computadora fue uno de los puntos de quiebre para que este nuevo contexto pueda tomar protagonismo en diversos aspectos de la época moderna. Gates (1996, como se citó en Barja, 2016) cuenta que el primer ordenador se llamó ENIAC y fue desarrollado por John Presper y John Mauchly en la Universidad de Pensilvania, con el objetivo de resolver problemas de cálculo.

IBM no desaprovechó esta coyuntura y empezó a comercializar más ordenadores con esta nueva tendencia moderna, hasta el punto de llegar a Japón, donde el concepto de ordenador creó bastante expectativa e investigación (Briggs \& Burke, 2002). Para 1961, las computadoras ya eran toda una novedad; por el contrario, los ordenadores portátiles eran una especie de paradigma que ya se veía concretar. La prensa tenía que ser parte de esta coyuntura, en consecuencia, las redacciones que contaban con máquinas de escribir y métodos antiguos, tenían que pasar por un proceso de convergencia hacia la nueva era digital. Cuando se habla de convergencia, es en referencia a la evolución del periodismo tradicional al esquema moderno. En este sentido, sostiene Jenkins (2006, como se citó en Barja, 2016) que "la convergencia periodística es un concepto dinámico y poliédrico. El carácter heterogéneo de este proceso se debe a que afecta tanto al modo de producir los contenidos como la forma en que estos se consumen" (p.106).

Por lo explicado, Luzón (2000) tiene una postura que afianza la idea de que la plataforma digital es un nuevo medio de comunicación:

Con la renovación de los medios estamos asistiendo también a una transformación de las formas y de los conceptos teóricos que utilizábamos en la investigación tradicional de los mass media. La comunicación en red no es solo un nuevo formato de transmisión de la información, debe ser considerado como un nuevo medio de comunicación, con sus propias reglas, lenguaje y terminología específica (p.2). 
Internet poseía cuatro características que hacían de su función una práctica innovadora: el hipertexto, capacidad multimedia, interactividad e interfase (Sánchez, 2007). Primero, el hipertexto, el cual se presenta como texto, en el cual también hay contenido que enlaza con otro contenido similar o de interés. De esta manera, uno puede vincular un documento con otro, de tal forma que la información sea más extensa y compacta. Segundo, la capacidad multimedia se refiere a la competencia de implementar todo tipo de archivos audiovisuales, para así generar más efectividad y enganche con el receptor. Tercero, la interactividad, que se trata de una comunicación bastante fluida entre emisor y receptor a través de cualquier medio; por ello, este proceso de interacción debe ser bastante eficaz para que ambas partes puedan estar de acuerdo con lo mostrado o expresado. Por último, la interfase, la cual se refiere al diseño de la página web o la estructura digital del medio de comunicación, de tal manera que sea atractivo para el público y este pueda navegar con mucha facilidad y rapidez.

El periodismo digital tuvo nuevas herramientas para generar contenidos y así también un espacio para desarrollarse como profesión. De esta manera, la convergencia del medio tradicional al impreso fue vital para que las empresas periodísticas puedan tener nuevos modelos de negocios. El Perú no tenía un soporte estatal para esta nueva era, por ello se entiende que la llegada de Internet y su posterior aplicación fue por una razón social, cultural y, por supuesto, un privilegio para las personas que tenían poder económico (Sánchez, 2007).

Para 1991 se creó la Red Científica Peruana (RCP), que tenía como objetivo reunir a todos los centros académicos que quisieran ejecutar investigaciones y así formar parte de la red global (Yezers'ka \& Zeta, 2016). Dicha organización académica también influyó en la decisión de diversas empresas de comunicaciones que querían ofrecer este valorado servicio y estar a la vanguardia del primer mundo.

Se debe recordar que, en 1990, los diarios que lideraban las preferencias en este país aún no tenían formato digital y que, cinco años después, la historia cambiaría por completo. Caretas, conocida revista nacional, fue el primer medio en publicar notas en una página web. Para 1996, La República introdujo al mercado nacional su formato digital, convirtiéndose en el primer diario peruano en tener su edición en Internet. El director Gustavo Mohme Seminario, en 2004, recordó que desde esa fecha (1996), la "aldea global se ha estrechado cada vez más para los millares de lectores que en cinco conti- 
nentes nos leen diariamente y que se sienten conectados al Perú" (Yezers'ka, 2008, p.73).

En paralelo, el diario estatal y el más antiguo de América Latina, El Peruano, ya se preparaba para mostrar su edición digital y no dudó en presentarla el 28 de julio de 1996. La novedad que traía este medio de comunicación era la difusión del mensaje presidencial del entonces mandatario, Alberto Fujimori (Yezers'ka, 2008). Por otro lado, considerado como el decano de la prensa peruana y uno de los más influyentes de este país, el diario El Comercio tuvo que esperar hasta el 15 de enero de 1997 para presentar su edición web, la cual fue presentada en la revista PC World Perú (Yezers'ka, 2008).

Para el año 2000, cerca de 25 diarios peruanos ya poseían su formato digital, por lo que la brecha digital estaba acortándose poco a poco. Para Yezers'ka (2008), existen tres factores para concretar esta convergencia de las empresas periodísticas de lo tradicional a lo moderno.

Confiaban, sobre todo, en las expectativas que podría significar internet para la prensa en el futuro, desconocido para el periodismo en aquel momento. Asimismo, la mitad de los especialistas encuestados relaciona el interés en publicar en la Red con los posibles beneficios económicos y con la oportunidad de ampliar las audiencias a costa de los peruanos residentes en otros países (p.75).

Para Mendoza (2017), "las empresas periodísticas viven un proceso de reconversión sin vuelta atrás, que ha implicado un cambio tanto en las condiciones de producción o rutinas periodísticas, como en el concepto de lo que hoy se reconoce como información" (p.78).

Para el año 2008, las ediciones digitales de El Comercio, Perú21, Peru.com y La República eran las más vistas, a pesar de que el número de lectores de diarios impresos seguía superando a los de la plataforma web. Según un estudio de Ipsos Apoyo Opinión y Mercado (2010, como se citó en Mendoza, 2016), se conoció que existían cerca de 4.6 millones de usuarios, de los cuales el $12 \%$ pertenecían a Lima Metropolitana y tenían servicio de internet propio.

Ya en 2018, el Grupo El Comercio (GEC) llegó a tener a su cargo toda la empresa periodística conformada por los diarios El Comercio, Perú21, Publimetro, Trome, Depor, Ojo, Correo, Bocón y Perú.com. En ese sentido, según 
dicho estudio, la oferta digital estaba dominada por el decano de la prensa peruana, ya que su inversión publicitaria llegaba a los US\$ 107 millones y, a la par, esto también se elevaba por la introducción de las redes sociales, principalmente Facebook.

\section{El deporte desde el periodismo y el fútbol como tema de masas}

\subsection{La perspectiva del deporte a través de los medios de comunicación}

Es evidente que la convergencia de los diarios tradicionales al mundo digital fue todo un fenómeno social y cultural. El periodismo se ha visto influenciado de manera alentadora desde la creación de los ordenadores hasta la aparición de Internet. Sin embargo, las divisiones de esta profesión como la de investigación, deportiva, espectáculos, economía, entre otras, se han visto reinventadas, de tal manera que su actualización es continua.

La prensa, para una sociedad, es relevante a través de sus diversos canales; por ello, Regalado (2006) reafirma esta idea de la siguiente manera: "Los medios de comunicación son instituciones de reproducción ideológica y de penetración de valores en la masa que los consume, la actividad del receptor se asocia con la alienación de que son víctimas los diversos sectores de la población, frente a los reproductores del poder" (p.92).

Para esto es importante indicar que la relevancia de los deportes como tema principal a lo largo de la historia también fue producto de una manifestación social. Así lo plasman Pujadas \& Santacana (2012):

Indudablemente, se trata de un fenómeno fundamentalmente urbano, y vinculado a determinadas ciudades industriales y comerciales en las que, no solo existe un flujo de ciudadanos de diferentes procedencias, sino que emerge una demanda real acerca de un modelo de ocio moderno, burgués y vinculado a la actividad física (p.142).

Para el siglo XX, el desarrollo de esta rama del periodismo ya estaba totalmente marcada, tanto en los emisores como en los receptores. En efecto, el discurso de los medios deportivos ya lograba afianzarse y así se conoció que el lenguaje de esta especialidad "tenía nuevas expresiones lingüísticas, interpretaciones, metáforas, símiles; que dieron paso a la crónica deportiva, 
además del empeño por el cultivo de las estadísticas que permitían un seguimiento a la progresión de las marcas deportivas establecidas por los pioneros de las incipientes disciplinas" (Arango, 2005, p.142).

Durante años, el periodismo deportivo no fue bien visto desde otras categorías, dado que no estaría cumpliendo su rol de objetividad, exactitud y control en los grupos de poder (Mellado \& Scherman, 2018). Paralelamente, también se le observa como un negocio, ya que las notas informativas deportivas están plagadas en los diarios al igual que los anuncios publicitarios (Domínguez, 2009).

\subsection{El fútbol como uno de los temas principales del periodismo}

A la par, también se habla de la relación entre los conceptos de deporte y espectáculo desde el periodismo. Para ello es necesario citar la definición que detalla Domínguez (2009), pues asegura que "probablemente el periodismo deportivo nazca también como el primer periodismo de entretenimiento, con publicaciones dedicadas a tratar asuntos que son entretenidos por excelencia (juegos, competencias, hazañas deportivas), donde la información da cuenta de ciertos hechos y entretiene a su vez" (p.73). Es importante indicar que el deporte, para efectos de esta investigación, tendrá como eje central al fútbol, el cual, para el investigador Galindo Cáceres (2009), está resumido de la siguiente manera:

Es un juego de conjunto, donde el movimiento es el eje de la composición del juego. Dos equipos se enfrentan, disputan el dominio de un balón, e intentan conseguir un gol, un tanto que se logra al introducir el balón en un marco de madera compuesto por tres palos, dos verticales y un horizontal que une a los otros dos a cierta altura sobre el piso (p.2).

Si bien es cierto, la explicación desarrollada es netamente sobre cómo se practica esta disciplina, también existen otras definiciones sobre este deporte desde otras posturas. Para Carrión \& Pérez (2006) es una destreza de unión colectiva, dado que se extiende más allá de su significado como actividad deportiva. Por ello, se transforma en un objeto cultural, económico y político.

El fútbol no se conocía como deporte oficial hasta el siglo XVIII. Sin embargo, su lugar de origen o inicio se le atribuyen a Inglaterra. En el caso del Perú, la llegada del fútbol no fue un hecho ajeno. El arribo también fue similar al 
de Argentina, aunque su apogeo fue más por la curiosidad de los sectores populares. Para Pulgar Vidal (2018), este deporte fue "expropiado tanto dentro como fuera de la cancha. Dentro, al jugarlo espontánea, intuitiva e imprevistamente. Fuera, al agregarlo a sus prácticas culturales de sociabilidad y solidaridad, produciéndose un encuentro de lo premoderno con una actividad de la modernidad" (p.24).

Según Basadre, el primer juego de fútbol en el Perú se desarrolló “el domingo 7 de agosto de 1892 , donde se enfrentaron dos equipos que combinaban ingleses y peruanos, que representaban a Lima y al puerto de El Callao" (como se citó en Alabarces, 2018, p.46). Un dato importante es que muchos peruanos, por esas épocas, tenían problemas para pronunciar la palabra "fútbol" y denominaron a este deporte como "fúlbol" o "fulbo" (Pulgar, 2018). Se podría decir que esta denominación se enlaza directamente con el público popular, dado que no había mucho conocimiento de otros idiomas e imperaba el lenguaje coloquial. La picardía también era parte de este contexto.

La prensa deportiva y de espectáculos, principalmente, también han formado parte de esta crítica, principalmente por la cantidad de información que se difunde a raíz de un rumor o información sin alguna confirmación oficial.

\section{Sensacionalismo}

\subsection{Definición del sensacionalismo y su utilidad en los periódicos}

La prensa en Estados Unidos e Inglaterra se venía consolidando desde el siglo XIX. Con la aparición de la prensa popular o masiva, esta "podía estimular o provocar la opinión con su juicio, pero no podía determinar de qué manera reaccionarían sus lectores" (Briggs \& Burke, 2002, p.237). Por ello, no se esperaba que los receptores tuvieran gran afición por las notas de chismes, rumores o de personas conocidas en ese tiempo. Las revistas, antes que los periódicos, brindaban este tipo de información, que tiempo después pasarían a llamarse tabloides. Gargurevich (1999) explica que, en Estados Unidos, apareció una revista donde se contaban confesiones, la cual tuvo una influencia para otros medios y fue sorpresiva para la prensa seria. $\mathrm{Su}$ contenido era una especie de distracción para el público, que estaba, de cierta manera, acostumbrado a recibir solo notas sobre política, economía, sociedad, entre otros. 
Hasta este punto, se denota que la demanda por información no tan formal era bastante llamativa para el público. No obstante, es necesario explicar por qué se introduce el término "sensacionalismo" a la prensa masiva. Para Nívea (1994), se explica esta estrategia informativa como:

Sensacionalizar las noticias es un modo de comunicación (...) por medio de la vedetización de acontecimiento y personajes que se localizan habitualmente en la periferia del orden instituido. El discurso de los periódicos populacheros se presenta como adecuado a las condiciones culturales y económicas de las clases populares (p.143).

Bajo este contexto, también se infiere que el medio de comunicación es el indicado para brindar este tipo de información sensacional. Sin embargo, el hecho de ser sensacional también es relacionado con la valoración del público. Ante esto, Redondo (2013) refuerza esta idea:

La prensa seria merecería una gran estimación social dada la responsabilidad que asume, al propiciar la reflexión de los ciudadanos sobre asuntos de relevancia e interés común y, por tanto, su implicación en la vida pública. La prensa sensacionalista, por su parte, rebajaría esa responsabilidad buscando, prioritariamente, el entretenimiento y la comercialidad (p.236).

Para Gómez (2013), el primero tiene una línea estructurada por titular, bajada, contenido; de tal manera que la información esté bien contada con un lenguaje claro y pueda tener todos los elementos periodísticos que respondan a las preguntas básicas como “¿qué?”, “¿quién?”, “¿cuándo?”, “¿dónde?” y “¿por qué?” Por su parte, el discurso sensacional tiene un lenguaje bastante informal, el cual solo busca causar visitas o nuevos lectores, sin pensar en la calidad periodística. Las fuentes podrían ser solo rumores y, a partir de esto, inferir que todo el contenido tiene un argumento poco verídico.

\subsection{Sensacionalismo como parte del discurso de los diarios deportivos}

En el contexto peruano, conocidos diarios como Depor y Libero, que son las dos plataformas deportivas con más nivel de aceptación y consumo en el público, también son materia de análisis respecto a su desempeño como medio de comunicación. Para Vargas (2018), Depor se ayudó de la última 
clasificación de la selección peruana a una Copa del Mundo para generar una línea discursiva relacionada al patriotismo. La objetividad periodística "minimizada por las herramientas literarias y marketeras de los editores del diario para poder crearse una trama que pueda enganchar de manera directa con el lector" (Vargas, 2018, p.24).

De la misma manera, Castillo (2013) evidenció que Depor tiene un "discurso verosímil y poco objetivo" (p.89), ya que, según su propio discurso, este diario intenta validar toda su información y se muestra como influyente para la sociedad; pero su contenido no muestra un adecuado manejo de fuentes y crea una verdad distante de la realidad de los hechos dentro del círculo de fanáticos deportivos (p.89).

El discurso de la prensa está alineado a la exageración de las noticias y magnificación de los personajes. Por ello, muchas veces el público critica y sugiere que este tipo de información no puede ser difundida, ya que confunde y no logra ser del todo seria. "Bajo la denominación de tabloidización, infoentretenimiento, trivialización o banalización de contenidos, desde los años 90 del pasado siglo distintos estudios han dado cuenta del proceso de erosión en la calidad de los medios, en referencia a la deriva hacia asuntos y formas características de la prensa sensacionalista" (Palau-Sampio, 2016, p.64).

Sobre la convergencia hacia la plataforma digital y los nuevos modelos de negocio, la periodista Rojo (2019) indica que "lo que parecía una alternativa sin futuro ha pasado a convertirse en un modelo indispensable para el futuro de los periódicos tradicionales. Paradójicamente, el carácter global de Internet ha impulsado el periodismo de proximidad llevado a cabo por los medios regionales" (p.1).

\section{Clickbait}

\subsection{Conceptualización y su aplicación en los diarios digitales}

Lo que llama la atención del sensacionalismo durante estos últimos años, es la utilización de los recursos para captar la atención y mantener a su audiencia. Titulares como "¿Claudio Pizarro ya piensa seriamente en decir adiós al fútbol?”, “¿Así vale? Y no es Messi: el jugador que 〈valdría〉 más que Mbappé y Neymar para 'Transfermarkt"” o "Loco' al Barza"; dan la clara idea de que la información no llega a ser precisa y que se invita al lec- 
tor para que pueda saber más del tema. Sin embargo, se genera la pregunta: ¿realmente estos titulares están ofreciendo una información fidedigna y el contenido es de calidad? Este contenido suele ser bastante soft y no tiene gran relevancia para los lectores. Los tópicos desarrollados ya no suelen ser cubiertos de manera puntual por los periodistas y se prioriza la información que demanda el público. Ante esto, Palau-Sampio (2016) explica que "esta circunstancia coincide con titulares que presentan rasgos característicos de la prensa popular, que actúan más como anzuelo para captar la curiosidad -y de paso producir ingresos cada vez que se pincha sobre ellos- que como elementos informativos" (p.63).

Para objetivos de esta investigación, se hará foco en la forma de titular las notas informativas y generar expectativa, la cual ya viene siendo utilizada por la prensa en general. Sin embargo, en tópicos deportivos y de espectáculos en plataformas web, su uso es frecuente y llamativo.

Se hace referencia al clickbait, que por su significado a través del diccionario de Oxford (2020), es el "material puesto en Internet para atraer la atención y alentar a los visitantes a hacer clic en un enlace a una página web en particular”. Es importante mencionar la postura de Gallur, García \& López (2017), quienes remiten que el contexto informativo de los últimos años ha evolucionado tan rápidamente que los medios de comunicación prácticamente tienen que actualizar todo al momento; la rapidez y la inmediatez ya son parte de los diarios, los cuales tienen que informar al minuto todo lo que pasa alrededor.

Por su parte, Learreta (2017) sostiene que el ingreso de estos nuevos recursos informativos también está relacionado con la convergencia de los diarios, debido a que sus modelos de negocio han cambiado ampliamente, buscando así al concepto de publicidad como brazo derecho para sostenerse inevitablemente. Esto quiere decir que, desde la convergencia del modelo tradicional al digital, los diarios han encontrado un nuevo nicho de ingreso, el cual, como ya es utilizado de manera extensa, tiene que ser explotado de la mejor manera, buscando generar más y más fuentes de financiamiento.

Ante esto, es necesario indicar que la convergencia también trajo una caída para los medios impresos a nivel mundial. El hecho de cambiar del medio tradicional al analógico tuvo que generar una nueva formar de informar y de generar ingresos. Según Bazaco, Redondo \& Sánchez-García (2019): 
El entorno actual de los medios de comunicación registra una severa caída de las tiradas en papel de los diarios y un número de suscripciones insuficiente para sostener las redacciones, de manera que la prensa depende cada vez más de la publicidad online que es la única partida publicitaria que se ha visto incrementada en los últimos años (p.95).

La generación de este recurso informativo, como se ha mostrado, viene por el sensacionalismo, como parte del discurso de un diario que quiere generar expectativa; y por el hecho de generar ingresos a partir de estrategias que no son las más precisas, pero que permiten enganche directo con el público.

\section{Metodología}

La investigación es aplicada, dado que el problema es de carácter público y responde a una problemática real o práctica. Se requiere de un análisis para saber cómo funciona el clickbait y su proceso en las notas periodísticas deportivas.

Es importante indicar que el problema de investigación es práctico. Esto se debe a que la estrategia del clickbait en Depor.com es tangible, ya que las notas informativas son reales y no se está diseñando un escenario textual relativo.

Esta investigación tiene un nivel descriptivo, pues se quiere conseguir la explicación y demostración de un proceso periodístico, el cual nace a partir de un medio de comunicación con el fin de difundir contenido noticioso.

El proyecto es no experimental y es de tipo cualitativo, ya que no se manipularán variables o el sentido de las notas informativas. Se observarán los diversos contenidos de las notas informativas y se indagarán por separado; por ello, no habrá alguna adulteración a los objetos de análisis.

Con relación a las técnicas o instrumentos de recolección de datos, se aplicará la técnica de análisis de contenido mediante el instrumento de matriz de análisis. Respecto al universo en la presente investigación, este son las notas informativas que se difunden por los diversos medios de comunicación. La población son las notas informativas publicadas en la web oficial de Depor. com entre noviembre de 2019 y enero de 2020 y la muestra en total son tres 
notas informativas de Depor.com entre noviembre de 2019 y enero de 2020, que informan sobre la probable venta de Paolo Guerrero a Boca Juniors.

\section{Resultados}

\section{Tabla 1}

Análisis de contenido a notas $N^{\circ} 1 A$ y $1 B$ de Depor.com, del 26 de noviembre de 2019

\begin{tabular}{|c|c|}
\hline \multicolumn{2}{|c|}{ Variable 1: Sentido de la nota informativa } \\
\hline Titular & $\begin{array}{l}\text { Sería invencible: el poderoso XI de Boca con Paolo Gue- } \\
\text { rrero que iría por la Copa Libertadores } 2020 \text { [FOTOS]. }\end{array}$ \\
\hline Sentido del titular & $\begin{array}{l}\text { Se informa sobre una suposición, por ello, también la pa- } \\
\text { labra "invencible" genera un titular muy expectante y de } \\
\text { enganche con el público. }\end{array}$ \\
\hline Bajada & $\begin{array}{l}\text { A propósito de los últimos rumores que vinculan a Pao- } \\
\text { lo Guerrero con Boca Juniors, te mostramos cómo sería el } \\
\text { once titular del cuadro "xeneize" con el delantero peruano } \\
\text { en sus filas. ¿Te lo imaginas? }\end{array}$ \\
\hline Sentido de la bajada & $\begin{array}{l}\text { Señalan que los rumores son la fuente de esta noticia. Por } \\
\text { ello, se toman la atribución de generar una suposición. }\end{array}$ \\
\hline $\begin{array}{l}\text { Uso de fuentes o refe- } \\
\text { rencias }\end{array}$ & $\begin{array}{l}\text { Sí: mencionan a la "prensa argentina" como la principal re- } \\
\text { ferencia para suponer la llegada del futbolista peruano a la } \\
\text { Superliga Argentina. }\end{array}$ \\
\hline Citas & No hay citas. \\
\hline $\begin{array}{l}\text { Verbos en } \\
\text { condicional }\end{array}$ & “Sería”, “iría”, “estaría”, “vendría”, "luciría”, “daría”. \\
\hline \multicolumn{2}{|c|}{ Variable 2: Estrategia digital } \\
\hline Clickbait & $\begin{array}{l}\text { Sí, ya que el titular invita a suponer un probable escena- } \\
\text { rio sin alguna confirmación oficial. El uso de preguntas y } \\
\text { verbos en condicional demuestran que los rumores son la } \\
\text { fuente directa de esta nota. }\end{array}$ \\
\hline
\end{tabular}




\begin{tabular}{|l|l|}
\hline Variable 3: Características del discurso sensacionalista \\
\hline $\begin{array}{l}\text { Uso de apodos o so- } \\
\text { brenombres }\end{array}$ & $\begin{array}{l}\text { El club Boca Juniors es mencionado como "xeneize" y Pao- } \\
\text { lo Guerrero es denominado como "Depredador". }\end{array}$ \\
\hline Lenguaje coloquial & $\begin{array}{l}\text { El uso de apodos y la línea discursiva vinculada con la pa- } \\
\text { sión o subjetividad hacen que la nota informativa deje su } \\
\text { rigor objetivo y se plasme una narración de crónica. }\end{array}$ \\
\hline $\begin{array}{l}\text { Exageración de los } \\
\text { hechos y magnifica- } \\
\text { ción de las personas }\end{array}$ & $\begin{array}{l}\text { Frases como "Si existe un jugador en la actualidad por el } \\
\text { que cualquier equipo del fútbol argentino estaría dispues- } \\
\text { hayalago para el jugador desde el propio diario. Se ha- } \\
\text { blaría ya no un jugador, sino de un personaje. El fichaje } \\
\text { del jugador peruano se suele cubrir y redactar de manera } \\
\text { exagerada, debido a que se demuestra como una acción es- } \\
\text { pectacular. }\end{array}$ \\
\hline
\end{tabular}

Nota: Elaboración propia.

\section{Tabla 2}

Análisis de contenido a notas $N^{\circ} 2 A$ y $2 B$ de Depor.com, del 27 de noviembre de 2019

\begin{tabular}{|l|l|}
\hline Variable 1: Sentido de la nota informativa \\
\hline Titular & $\begin{array}{l}\text { Paolo cada vez más cerca de Boca: Burdisso llegó a Brasil } \\
\text { para presentar oferta formal al Internacional }\end{array}$ \\
\hline Sentido del titular & $\begin{array}{l}\text { Se concreta la idea de que Paolo Guerrero estaría cerca de } \\
\text { fichar por Boca Juniors. Por ello informan que un directivo } \\
\text { del club argentino ha viajado a Brasil. }\end{array}$ \\
\hline Bajada & $\begin{array}{l}\text { Paolo Guerrero es el gran objetivo de Boca Juniors para } \\
\text { 2020 y la dirección deportiva del club bonaerense ya inició } \\
\text { las negociaciones para ficharlo. }\end{array}$ \\
\hline Sentido de la & $\begin{array}{l}\text { La bajada también afirma rotundamente que el club argen- } \\
\text { tino ya inició el tema del traspaso; pero, no hay fuentes ofi- } \\
\text { ciales. }\end{array}$ \\
bajada & $\begin{array}{l}\text { Sí: la única cita es la mención a una radio, de la cual desglo- } \\
\text { san la información y arman la redacción. }\end{array}$ \\
\hline $\begin{array}{l}\text { Uso de fuentes o rased } \\
\text { ferencias }\end{array}$ & \\
\hline
\end{tabular}




\begin{tabular}{|c|c|}
\hline Citas & $\begin{array}{l}\text { “Tal y como informa Radio Grenal, Burdisso quiere presen- } \\
\text { tarle una propuesta formal al 'Depredador' para que tenga } \\
\text { conocimiento del verdadero interés de la entidad argentina”. }\end{array}$ \\
\hline $\begin{array}{l}\text { Verbos en } \\
\text { condicional }\end{array}$ & "Reunirá", "gustaría”, "quiere presentarle” \\
\hline \multicolumn{2}{|c|}{ Variable 2: Estrategia digital } \\
\hline Clickbait & $\begin{array}{l}\text { Sí, afirman rotundamente que ya se iniciaron los trámites } \\
\text { o negociaciones entre Boca Juniors y Paolo Guerrero. Sin } \\
\text { embargo, citan a una fuente que lanzó una primicia. No hay } \\
\text { una confirmación oficial y solo es un rumor. }\end{array}$ \\
\hline \multicolumn{2}{|c|}{ Variable 3: Características del discurso sensacionalista } \\
\hline $\begin{array}{l}\text { Uso de apodos o } \\
\text { sobrenombres }\end{array}$ & $\begin{array}{l}\text { Sí: Boca Juniors es mencionado como “xeneize”. Además, } \\
\text { por los colores del club, es señalado como “azul y oro”. Paolo } \\
\text { Guerrero es llamado "Depredador" o el “9”. }\end{array}$ \\
\hline Lenguaje coloquial & $\begin{array}{l}\text { Sí: el discurso de la nota informativa tiene una redacción } \\
\text { vinculada a la crónica. Empieza con una frase como "Otro } \\
\text { peruano a la Bombonera", magnificando la contratación de } \\
\text { Paolo Guerrero. Se apela a la sencillez, de tal manera que la } \\
\text { presencia de apodos también forme una línea más amena. }\end{array}$ \\
\hline $\begin{array}{l}\text { Exageración de los } \\
\text { hechos y magnifica- } \\
\text { ción de las personas }\end{array}$ & $\begin{array}{l}\text { Se recurre a una suposición para generar expectativa. A la } \\
\text { par, se menciona a Paolo Guerrero como "el goleador histó- } \\
\text { rico de la selección peruana". No obstante, no citan un argu- } \\
\text { mento para señalar esta calificación. }\end{array}$ \\
\hline
\end{tabular}

Nota: Elaboración propia.

\section{Tabla 3}

Análisis de contenido anotas $N^{\circ} 3 A$ y $3 B$ de Depor.com, del 29 de noviembre de 2019

\begin{tabular}{|l|l|}
\hline Variable 1: Sentido de la nota informativa \\
\hline Titular & $\begin{array}{l}\text { Paolo Guerrero ya tiene fecha de llegada a Boca Juniors y } \\
\text { develan cuánto ganará como "Xeneize". }\end{array}$ \\
\hline Sentido del titular & $\begin{array}{l}\text { A primera vista, se observan que las negociaciones habrían } \\
\text { llegado a buen puerto. Por ello, ya existe un día para presen- } \\
\text { tar a Paolo Guerrero y, además, se puede conocer su salario. }\end{array}$ \\
\hline
\end{tabular}




\begin{tabular}{|c|c|}
\hline Bajada & $\begin{array}{l}\text { Según Martín Liberman, las negociaciones entre Boca Ju- } \\
\text { niors e Internacional por Paolo Guerrero están muy avan- } \\
\text { zadas. }\end{array}$ \\
\hline Sentido de la bajada & $\begin{array}{l}\text { En el texto complementario, se cita al conocido periodis- } \\
\text { ta argentino, quien confirmó que las negociaciones entre el } \\
\text { club y el futbolista peruano estarían por consolidarse. }\end{array}$ \\
\hline $\begin{array}{l}\text { Uso de fuentes o re- } \\
\text { ferencias }\end{array}$ & $\begin{array}{l}\text { Sí: se menciona al periodista Martín Liberman como fuen- } \\
\text { te principal y argumento de la nota. Asimismo, también se } \\
\text { abre otra nota secundaria, donde añaden una declaración } \\
\text { del agente de Paolo Guerrero, Francesco Balbi. }\end{array}$ \\
\hline Citas & $\begin{array}{l}\text { "Sería muy raro que Paolo no llegue", dijo Liberman en FOX } \\
\text { Sports. } \\
\text { "A Paolo (Guerrero) le encantaría ir a Argentina y, sobre } \\
\text { todo, a Boca", admitió el empresario del '9' peruano. Eso sí, } \\
\text { la entidad 'azul y oro' tendrá que hacer un esfuerzo econó- } \\
\text { mico importante para incorporar al atacante. } \\
\text { "La cláusula de salida tiene un costo de } 4.5 \text { millones de dó- } \\
\text { lares y sin eso es imposible que salga del Inter", añadió Balbi, } \\
\text { quien reconoció que hay disposición por parte del futbolis- } \\
\text { ta. } \\
\text { "Él está esperando que pasen los comicios para que se sien- } \\
\text { ten a negociar de forma más definitiva. Paolo estaría feliz de } \\
\text { ir a Boca, pero hay que esperar", manifestó al espacio depor- } \\
\text { tivo radial. }\end{array}$ \\
\hline $\begin{array}{l}\text { Verbos en condicio- } \\
\text { nal }\end{array}$ & "Pasaría”, "tendría”, "sería”, "encantaría”, "estaría”. \\
\hline \multicolumn{2}{|c|}{ Variable 2: Estrategia digital } \\
\hline Clickbait & $\begin{array}{l}\text { Sí, ya que el titular afirma que existe una fecha de arribo de } \\
\text { Paolo Guerrero a Boca Juniors. No obstante, las fuentes no } \\
\text { son oficiales y se prestan a interpretaciones. }\end{array}$ \\
\hline $\begin{array}{l}\text { Uso de apodos o } \\
\text { sobrenombres }\end{array}$ & $\begin{array}{l}\text { Sí: Boca Juniors es mencionado como "xeneize", "Casa ama- } \\
\text { rilla" y "azul y oro". Por su lado, el Club Internacional es lla- } \\
\text { mado "Colorado" y Paolo Guerrero "Depredador". }\end{array}$ \\
\hline Lenguaje coloquial & $\begin{array}{l}\text { Sí: el lenguaje sencillo y digerible es recurrente a lo largo de } \\
\text { todo el texto. }\end{array}$ \\
\hline
\end{tabular}




\begin{tabular}{|l|l|}
\hline $\begin{array}{l}\text { Exageración de los } \\
\text { hechos y magnifica- } \\
\text { ción de las personas }\end{array}$ & $\begin{array}{l}\text { Desde un inicio, se afirma que no falta nada para confirmar } \\
\text { la contratación de Paolo Guerrero a Boca Juniors o que esto } \\
\text { mación, pero exagerando de manera irresponsable, pues no } \\
\text { existe argumento oficial para esas aseveraciones. }\end{array}$ \\
\hline
\end{tabular}

Nota: Elaboración propia.

\section{Tabla 4}

Análisis de contenido a notas $N^{\circ} 4 A$ y $4 B$ de Depor.com, del 23 de diciembre de 2019

\begin{tabular}{|l|l|}
\hline Variable 1: Sentido de la nota informativa \\
\hline Titular & $\begin{array}{l}\text { ¿Llamará a Paolo? Ya habría fecha para el anuncio de Russo } \\
\text { en Boca Juniors. }\end{array}$ \\
\hline Sentido del titular & $\begin{array}{l}\text { A partir de una confirmación del probable próximo entre- } \\
\text { nador de Boca Juniors, se produce, según Depor, un rumor } \\
\text { sobre la llegada de Paolo Guerrero. }\end{array}$ \\
\hline Bajada & $\begin{array}{l}\text { ESPN asegura que Miguel Ángel Russo habría aceptado la } \\
\text { oferta de Boca y sería anunciado DT este jueves. }\end{array}$ \\
\hline Sentido de la bajada & $\begin{array}{l}\text { El diario menciona la fuente que confirma esta noticia. Sin } \\
\text { embargo, utiliza verbos en condicional. }\end{array}$ \\
\hline $\begin{array}{l}\text { Uso de fuentes o re- } \\
\text { ferencias }\end{array}$ & $\begin{array}{l}\text { Sí: la nota utiliza un anuncio de la cadena deportiva argen- } \\
\text { tina, ESPN. }\end{array}$ \\
\hline Citas & $\begin{array}{l}\text { "Miguel Ángel Russo sería el próximo entrenador de Boca } \\
\text { Juniors, y su anuncio se haría este jueves, según indicó la } \\
\text { cadena de televisión internacional, ESPN". }\end{array}$ \\
\hline $\begin{array}{l}\text { Verbos en condicio- } \\
\text { nal }\end{array}$ & "Habría", "sería", "haría", "regresaría", "volverían", "podrían". \\
\hline Variable 2: Estrategia digital \\
\hline Clickbait & $\begin{array}{l}\text { Sí, dado que desde el titular se trata de relacionar al estratega } \\
\text { con la llegada de Paolo Guerrero. No hay coherencia. }\end{array}$ \\
\hline
\end{tabular}




\begin{tabular}{|l|l|}
\hline \multicolumn{2}{|l|}{ Variable 3: Características del discurso sensacionalista } \\
\hline $\begin{array}{l}\text { Uso de apodos o } \\
\text { sobrenombres }\end{array}$ & Sí: Club Boca Juniors es mencionado como 'xeneize'. \\
\hline Lenguaje coloquial & Sí: hay un solo apodo como parte de un discurso informal. \\
\hline $\begin{array}{l}\text { Exageración de los } \\
\text { hechos y magnifica- } \\
\text { ción de las personas }\end{array}$ & $\begin{array}{l}\text { Al referirse a Miguel Ángel Russo, se habla de sus logros pa- } \\
\text { sado halago }\end{array}$ \\
\hline
\end{tabular}

Nota: Elaboración propia.

\section{Tabla 5}

Análisis de contenido a notas $N^{\circ} 5 A$ y $5 B$ de Depor.com, del 03 de enero de 2020

\begin{tabular}{|l|l|}
\hline Variable 1: Sentido de la nota informativa \\
\hline Titular & $\begin{array}{l}\text { Boca se reunió con agentes de Paolo Guerrero para acordar } \\
\text { su pase y decisión final será de Riquelme }\end{array}$ \\
\hline Sentido del titular & $\begin{array}{l}\text { Se afirma un acercamiento entre el club argentino y se anun- } \\
\text { cia que la decisión final del fichaje la tiene el directivo de } \\
\text { Boca Juniors. }\end{array}$ \\
\hline Bajada & $\begin{array}{l}\text { Según 'TyC Sports', Boca Juniors y la gente que representa } \\
\text { a Paolo Guerrero se reunieron este viernes en Argentina y } \\
\text { mostraron un preacuerdo. }\end{array}$ \\
\hline Sentido de la bajada & $\begin{array}{l}\text { Anuncian la fuente de esta confirmación. Asimismo, mues- } \\
\text { tran que tanto la representación del jugador peruano como } \\
\text { del club, tienen buenos tratos. }\end{array}$ \\
\hline $\begin{array}{l}\text { Uso de fuentes o re- } \\
\text { ferencias }\end{array}$ & $\begin{array}{l}\text { Sí: la nota se basa en un anuncio del medio argentino 'TyC } \\
\text { Sports. }\end{array}$ \\
\hline Citas & $\begin{array}{l}\text { "Dirigentes del club de la Ribera mantuvieron una reunión } \\
\text { con el grupo que maneja al Depredador y ya tienen un bo- } \\
\text { rrador de lo que costaría incorporar al jugador. Más allá de } \\
\text { la cuestión económica, cabe destacar que las partes mostra- } \\
\text { ron muy buena predisposición para que el pase se haga”, pu- } \\
\text { blicó 'TyC Sports. }\end{array}$ \\
\hline $\begin{array}{l}\text { Verbos en condicio- } \\
\text { nal }\end{array}$ & "Costaría”. \\
\hline
\end{tabular}




\begin{tabular}{|l|l|}
\hline Variable 2: Estrategia digital \\
\hline Clickbait & $\begin{array}{l}\text { Sí, pues afirman que directivos de Boca Juniors se reunieron } \\
\text { con un grupo cercano a Paolo Guerrero, infiriendo que su } \\
\text { pase es una realidad. }\end{array}$ \\
\hline Variable 3: Características del discurso sensacionalista \\
\hline $\begin{array}{l}\text { Uso de apodos o } \\
\text { sobrenombres }\end{array}$ & $\begin{array}{l}\text { Sí: Club Boca Juniors es mencionado como "Casa Amarilla" } \\
\text { y Paolo Guerrero como "Depredador". }\end{array}$ \\
\hline Lenguaje coloquial & Sí: el uso de apodos muestra que el mensaje es informal. \\
\hline $\begin{array}{l}\text { Exageración de los } \\
\text { hechos y magnifica- } \\
\text { ción de las personas }\end{array}$ & $\begin{array}{l}\text { Se busca exagerar una reunión, de tal manera que se genera } \\
\text { duda sobre qué sucedió en este encuentro entre representan- } \\
\text { tes de Boca Juniors y Paolo Guerrero. }\end{array}$ \\
\hline
\end{tabular}

Nota: Elaboración propia.

\section{Tabla 6}

Análisis de contenido a notas $N^{\circ} 6 A$ y $6 B$ de Depor.com, del 10 de enero de 2020

\begin{tabular}{|l|l|}
\hline Variable 1: Sentido de la nota informativa \\
\hline Titular & $\begin{array}{l}\text { Está difícil, pero sueña con él: Russo no descartó el fichaje de } \\
\text { Paolo Guerrero por Boca Juniors. }\end{array}$ \\
\hline Sentido del titular & $\begin{array}{l}\text { El titular informa que el técnico del club argentino aún sigue } \\
\text { pensando en el futbolista peruano, a pesar de que, en el ini- } \\
\text { cio, se utiliza una frase como "Está difícil, pero..." }\end{array}$ \\
\hline Bajada & $\begin{array}{l}\text { El entrenador Miguel Ángel Russo no ha descartado la in- } \\
\text { corporación del peruano Paolo Guerrero a Boca Juniors en } \\
\text { el presente mercado de fichajes de Argentina. }\end{array}$ \\
\hline Sentido de la bajada & $\begin{array}{l}\text { Sin ninguna información adicional o complemento. Así se } \\
\text { calificaría esta parte de la nota, dado que es una oración si- } \\
\text { milar al titular. }\end{array}$ \\
\hline $\begin{array}{l}\text { Uso de fuentes o } \\
\text { referencias }\end{array}$ & $\begin{array}{l}\text { Sí: la nota se basa en las declaraciones del DT, Miguel Ángel } \\
\text { Russo, en conferencia de prensa. }\end{array}$ \\
\hline
\end{tabular}




\begin{tabular}{|c|c|}
\hline Citas & $\begin{array}{l}\text { "Yo no doy descartado nada porque todavía tenemos el li- } \\
\text { bro de pases abierto y siempre las cosas pueden suceder", } \\
\text { dijo 'Miguelito' Russo sobre Paolo Guerrero este viernes en } \\
\text { conferencia de prensa en 'Casa Amarilla.' } \\
\text { "Entiendo lo que cuesta hoy en este país a niveles económi- } \\
\text { cos traer un jugador de afuera y todo lo que significa. Hay } \\
\text { muchos pasos que dar, antes era mucho más simple", agregó } \\
\text { el entrenador argentino de } 63 \text { años. }\end{array}$ \\
\hline $\begin{array}{l}\text { Verbos en condicio- } \\
\text { nal }\end{array}$ & No hay verbos en condicional \\
\hline \multicolumn{2}{|c|}{ Variable 2: Estrategia digital } \\
\hline Clickbait & $\begin{array}{l}\text { Sí, ya que la información juega con el hecho de la llegada del } \\
\text { futbolista, cuando el DT no se pronunciado sobre el tema. Se } \\
\text { trata de vincular las declaraciones genéricas con el tema de } \\
\text { Guerrero. }\end{array}$ \\
\hline \multicolumn{2}{|c|}{ Variable 3: Características del discurso sensacionalista } \\
\hline $\begin{array}{l}\text { Uso de apodos o } \\
\text { sobrenombres }\end{array}$ & $\begin{array}{l}\text { Sí: Miguel Ángel Russo como "Miguelito", Paolo Guerre- } \\
\text { ro como "Depredador" y el club Boca Juniors como "Casa } \\
\text { Amarilla". }\end{array}$ \\
\hline Lenguaje coloquial & $\begin{array}{l}\text { Sí: el recurrente uso de apodos hacia personas y clubes de- } \\
\text { portivos genera que el discurso sea llamativo e informal. }\end{array}$ \\
\hline $\begin{array}{l}\text { Exageración de los } \\
\text { hechos y magnifica- } \\
\text { ción de las personas }\end{array}$ & $\begin{array}{l}\text { No hay exageración o magnificación de los actores de la nota, } \\
\text { como son Miguel Ángel Russo o Paolo Guerrero. }\end{array}$ \\
\hline
\end{tabular}

Nota: Elaboración propia. 


\section{Tabla 7}

Análisis de contenido a notas $N^{\circ} 7 A$ y $7 B$ Depor.com del 16 de enero de 2020

\begin{tabular}{|c|c|}
\hline Titular & $\begin{array}{l}\text { Nada está dicho: Almendra tiene la clave para la llegada de } \\
\text { Paolo Guerrero a Boca Juniors. }\end{array}$ \\
\hline Sentido del titular & $\begin{array}{l}\text { Se sigue jugando con el rumor y el titular esconde una última } \\
\text { supuesta acción para que se consolide la llegada del jugador } \\
\text { peruano al club argentino. La frase "Nada está dicho" conso- } \\
\text { lida esta ambigüedad que sorprendería al público. }\end{array}$ \\
\hline Bajada & $\begin{array}{l}\text { Aún hay la posibilidad que Paolo Guerrero se ponga la ca- } \\
\text { miseta de Boca Juniors en el corto plazo, según reporta este } \\
\text { jueves la cadena FOX Sports. }\end{array}$ \\
\hline Sentido de la bajada & $\begin{array}{l}\text { Complementariamente, esta parte de la nota informativa no } \\
\text { suele mostrar más información que el titular. }\end{array}$ \\
\hline $\begin{array}{l}\text { Uso de fuentes o re- } \\
\text { ferencias }\end{array}$ & $\begin{array}{l}\text { Sí: se cita la declaración de Matías García, periodista del me- } \\
\text { dio argentino FOX Sports. }\end{array}$ \\
\hline Citas & $\begin{array}{l}\text { "Esta transferencia (la de Guerrero a Boca) en lo futbolístico, } \\
\text { para el cuerpo técnico y dirigentes, sería muy importante. } \\
\text { Contar con un futbolista de su recorrido agrada. Es mucho } \\
\text { dinero lo que tienen que poner sobre la mesa por su pase } \\
\text { y se abre la ventana de Almendra. En la MLS preguntaron } \\
\text { por él y están en tratativas", sostuvo Matías García, periodista } \\
\text { de FOX Sports. }\end{array}$ \\
\hline $\begin{array}{l}\text { Verbos en condi- } \\
\text { cional }\end{array}$ & "sería”. \\
\hline \multicolumn{2}{|c|}{ Variable 2: Estrategia digital } \\
\hline Clickbait & $\begin{array}{l}\text { Sí: desde el inicio, se juega con el concepto de "clave" para } \\
\text { conocer si se hará realidad o no la probable contratación de } \\
\text { Paolo Guerrero por parte del club argentino. La clave está es- } \\
\text { crita, literalmente. Por ello, se trata de esconder información. }\end{array}$ \\
\hline \multicolumn{2}{|c|}{ Variable 3: Características del discurso sensacionalista } \\
\hline $\begin{array}{l}\text { Uso de apodos o } \\
\text { sobrenombres }\end{array}$ & $\begin{array}{l}\text { Paolo Guerrero es mencionado como "Depredador" y el club } \\
\text { Boca Juniors denominado como 'xeneize'. }\end{array}$ \\
\hline Lenguaje coloquial & $\begin{array}{l}\text { El uso de apodos y un discurso alineado a una narración } \\
\text { donde los sujetos ya no son desde sus significados como su- } \\
\text { jetos, sino personajes, conforman un relato muy llamativo. }\end{array}$ \\
\hline
\end{tabular}




\begin{tabular}{|l|l|}
$\begin{array}{l}\text { Exageración de los } \\
\text { hechos y magnifi- } \\
\text { cación de las per- } \\
\text { sonas. }\end{array}$ & $\begin{array}{l}\text { Cuando se habla de Paolo Guerrero, en el texto, se denomina } \\
\text { como "prioridad". Por ello, se habla de una posición subjeti- } \\
\text { va, dado que el club no afirmó esta postura. Por el contrario, } \\
\text { podría ser la posición del medio. }\end{array}$ \\
\hline
\end{tabular}

Nota: Elaboración propia.

\section{Tabla 8}

Análisis de contenido a notas $N^{\circ} 8 A$ y $8 B$ de Depor.com, del 27 de enero de 2020

\begin{tabular}{|l|l|}
\hline Variable 1: Sentido de la nota informativa \\
\hline Titular & $\begin{array}{l}\text { Presidente de Boca Juniors cerró así el tema de Paolo Gue- } \\
\text { rrero }\end{array}$ \\
\hline Sentido del titular & $\begin{array}{l}\text { Se informa que el máximo líder del club argentino se pronun- } \\
\text { ció finalmente sobre la errada llegada de Paolo Guerrero a la } \\
\text { Superliga Argentina. }\end{array}$ \\
\hline Bajada & $\begin{array}{l}\text { Jorge Amor Ameal, titular de Boca Juniors, descartó la llega- } \\
\text { da de Paolo Guerrero a la institución argentina. }\end{array}$ \\
\hline $\begin{array}{l}\text { Sentido de la baja- } \\
\text { da }\end{array}$ & $\begin{array}{l}\text { Esta parte de la nota informativa solo adiciona el nombre del } \\
\text { presidente de Boca Juniors y asevera la misma idea del título. }\end{array}$ \\
\hline $\begin{array}{l}\text { Uso de fuentes o re- } \\
\text { ferencias }\end{array}$ & $\begin{array}{l}\text { Sí: se cita las declaraciones de Jorge Amor Ameal, presidente } \\
\text { de Boca Juniors, al programa "Superfútbol" de TyC Sports. }\end{array}$ \\
\hline Citas & $\begin{array}{l}\text { "Para mí, el tema está cerrado. Lo instaló la anterior dirigen- } \\
\text { cia. Román (Riquelme) habla con todo el mundo y también } \\
\text { trascendió. El DT está conforme con el plantel y sus jugado- } \\
\text { res. El tema del '9囚 empieza con la agenda del periodismo", } \\
\text { declaró el presidente del equipo. } \\
\text { "Hay gente que ni sabe quién es Guerrero ni lo vio jugar. Es- } \\
\text { peremos el tiempo necesario", manifestó. } \\
\text { "Estamos bien. El mercado de pases tiene un problema y se } \\
\text { llama dólares", añadió. }\end{array}$ \\
\hline $\begin{array}{l}\text { Verbos en condi- } \\
\text { cional }\end{array}$ & \begin{tabular}{l} 
No existen verbos en condicional en la nota informativa \\
\hline
\end{tabular} \\
\hline
\end{tabular}




\begin{tabular}{|c|c|}
\hline \multicolumn{2}{|c|}{ Variable 2: Estrategia digital } \\
\hline Clickbait & $\begin{array}{l}\text { Sí, el titular tiene una frase como "Cerró así". Por ello invita al } \\
\text { lector a conocer cómo fue este cierre. No hay una redacción } \\
\text { directa y clara. }\end{array}$ \\
\hline \multicolumn{2}{|c|}{ Variable 3: Características del discurso sensacionalista } \\
\hline $\begin{array}{l}\text { Uso de apodos o } \\
\text { sobrenombres }\end{array}$ & $\begin{array}{l}\text { Paolo Guerrero es mencionado como "el } 9 \text { de la selección pe- } \\
\text { ruana". }\end{array}$ \\
\hline Lenguaje coloquial & $\begin{array}{l}\text { Sí, el uso de sobrenombres o apelativos generan que el discur- } \\
\text { so tenga una línea informal. }\end{array}$ \\
\hline $\begin{array}{l}\text { Exageración de los } \\
\text { hechos y magnifi- } \\
\text { cación de las per- } \\
\text { sonas }\end{array}$ & $\begin{array}{l}\text { No hay exageración o magnificación de los hechos en las par- } \\
\text { tes de la nota informativa. }\end{array}$ \\
\hline
\end{tabular}

Nota: Elaboración propia.

\section{Discusión}

A través de la matriz de análisis de contenido, se ha realizado una indagación por separado sobre qué características presenta cada nota, de un total de ocho. Para ello, también resulta necesario realizar un análisis colectivo y evidenciar los resultados.

Depor.com es un medio informativo con una gran cantidad de público en su formato web. Ahí radica la importancia de estudiar su estrategia de redacción, ya sea en el caso específico de Paolo Guerrero o de personajes afines. Por lo expuesto en el análisis colectivo, es preciso señalar que todas las notas informativas tienen como base fundamental a dos ejes: Paolo Guerrero y Boca Juniors. Ambas son palabras clave y también conceptos que cualquier hincha del fútbol actualmente conoce $\mathrm{y}$, por tanto, está predispuesto a informarse o a conocer del tema. Es necesario indicar que, de por sí, estos conceptos son efectivos para llamar la atención en el lector, lo cual Depor.com identifica de manera óptima y sabe el efecto en su público objetivo.

Primero, los titulares llaman la atención de manera inmediata, dado que en las tablas de las noticias 2, 3, 5 y 8 se presentan afirmaciones que generan un enganche bastante efectivo con el lector. Algunos ejemplos son: "Paolo cada vez más cerca de Boca: Burdisso llegó a Brasil para presentar oferta formal al 
Internacional" o "Boca se reunió con agentes de Paolo Guerrero para acordar su pase y decisión final será de Riquelme". Al analizar estos párrafos, el lector entendería que la información es oficial y que el traspaso del futbolista peruano al club argentino ya es una realidad. Sin embargo, en el desglose de la información, la situación es otra, dado que las fuentes, las cuales son conocidas para el medio deportivo, no necesariamente pueden ser voceras oficiales de los clubes mencionados y menos confirmar algún rumor. Justamente, a partir de su naturaleza como rumor, es que Depor.com recoge esta especulación, cita a la referencia y titula de manera oficial, cometiendo un acto de falsedad hacia el lector.

Para contrastar esta postura, se añade la posición de Javier Gómez, autor mencionado en el marco teórico, quien explica que el discurso sensacional tiene un lenguaje bastante informal, el cual solo busca causar visitas o nuevos lectores, sin considerar la calidad periodística.

Se entiende que el titular y la bajada son complementos, donde la segunda parte suele tener información adicional que consolide al titular o pueda ser una respuesta de este. En ese sentido, las tablas de las notas 3, 4 y 5 son complementarias, pero de manera muy elemental. Sin embargo, las notas de las tablas 1, 2, 6, 7 y 8 suelen ser como una especie de "copiar y pegar" del título, pues o se desglosa el título con ayuda de artículos o no hay información adicional.

La redacción de Depor.com es informal o coloquial, por el recurrente uso de apodos o sobrenombres. En este caso en particular, están alineados a la cualidad o rasgos, por ejemplo, como 'Depredador', 'xeneize' y 'Casa amarilla, entre otros. En ese sentido, si bien en el marco teórico se indicó que el público objetivo del diario analizado puede tener ciertas características que se vinculan a una cultura popular, también se genera que otro tipo de público no pueda comprender el mensaje.

Ante esta evidencia, se reafirma la postura de Nívea (1994), quien menciona a la sensacionalización como un modo de comunicación que recurre a la "vedetización de acontecimientos y personajes" (p.143) que son de conocimiento muy popular. Por ello, según la autora, este tipo de discursos sensacionales responden a una demanda cultural y económica de las clases sociales.

Asimismo, también la presencia de verbos en condicional es más clara. En las siete primeras tablas, de las ocho en total, se identificó por lo menos una pa- 
labra en condicional, lo que traduce que la información no está contrastada en su totalidad y que la redacción del diario analizado apela a este criterio para informar. Sin embargo, suele generar una duda porque un verbo en condicional no está negando ni aceptando.

A partir de esta afirmación se trae a colación la perspectiva de Castillo, quien ya evidenció que, en el diario investigado, se intenta reafirmar la imagen de medio referente, pero que en la práctica esta no es objetiva. Paralelamente, también es importante indicar que la redacción en todas las notas tiene una relación con la crónica periodística, la cual conlleva un estilo de narración bastante llamativo y que, estéticamente, suele ser más llamativa para el lector. Es una forma de redacción que engancha al público. Por ello, hay una suerte de exageración para hablar sobre el jugador peruano o el hecho del supuesto traspaso.

Palau-Sampio sugiere que este tipo de información no puede ser publicada o comunicada, dado que es vehículo de confusión y no logra ser verídica. Ante esto, recurre a términos como la "tabloidización", "infoentretenimiento", "trivialización" o "banalización de contenidos", que son características de una prensa sensacionalista.

Por otra parte, el evidente y recurrente uso del clickbait en la parte inicial, está en todas las tablas de las notas informativas. Los titulares tienen dos estrategias para informar. Una de ellas es confirmar la contratación de Paolo Guerrero de manera oficial, lo cual no estaba probado. La otra es apelar a la duda textual para que el usuario se cuestione y, en caso quiera encontrar la respuesta a la interrogante planteada en el titular, necesariamente tenga que leer el desglose de la nota informativa.

Para Gallur, García \& López, esta práctica se explica en cuanto el contexto ha evolucionado de manera tan rápida que los medios de comunicación tienen que ser inmediatos y así remitir toda la información posible. Hasta se podría indicar que hay una cierta competencia entre medios, ya que su éxito depende de la velocidad con la que publican una primicia. En ese sentido, los titulares se alinean perfectamente con las novedades o primicias.

También se puede mostrar la perspectiva de Learreta, quien indica que el tema comercial de los medios de comunicación en el espacio digital está dando frutos y esto también recae en la forma de informar. Por ello, a partir de más visitas a las notas informativas web, más ingresos se concentrarán. El clickbait también tiene una influencia económica. 
Finalmente, es preciso indicar que, de manera colectiva, las notas informativas siempre mantienen el tema de Paolo Guerrero en tendencia y vigencia, a través de contenidos con titulares que generan enganche de clics.

\section{Conclusiones}

El medio investigado se encuentra en el ecosistema digital, donde la página web es su principal plataforma para difundir notas informativas durante todos los días sin ninguna pausa. Sin embargo, solo es contenido deportivo, por su línea editorial. En este sentido, su versatilidad le permite colocar imágenes, audios y videos, lo que se interpreta como material audiovisual.

Específicamente, para el tema de investigación -la probable contratación de Paolo Guerrero por parte de Boca Juniors entre 2019 y 2020-, Depor.com asumió una disposición total para informar sobre el mencionado hecho. Esto se debió a que resultaba relevante para el medio, ya sea por el futbolista en mención, como por los clubes deportivos que estaban involucrados: Boca Juniors e Internacional de Porto Alegre.

Desde la primera nota, con fecha del 11 de noviembre de 2019, hasta la última del 27 de enero de 2020, hay un evidente uso de recursos informativos relacionados con el sensacionalismo, como son el lenguaje coloquial, el uso de verbos en condicional, inicios de párrafos como crónicas periodísticas, exageración de hechos, magnificación de personajes y titulares, el clickbait o clic de enganche. En efecto, toda esta evidencia demuestra que Depor.com no informa con veracidad, credibilidad y rigurosidad sobre el tema Paolo Guerrero, pues toma como referencia principal a la especulación o el rumor. Esta tendencia produce que la mayoría de las notas tenga un formato incoherente e inverosímil: mientras el titular o la bajada confirman una información, esta finalmente se revela como una suposición o especulación en el desglose de la nota.

Respecto al clickbait, queda claro que este recurso se utiliza para producir que el diario tenga más atención y genere expectativa en el usuario. A raíz de esto, el receptor tiene curiosidad o se cuestiona sobre la información difundida y, por tanto, querrá ingresar a la página web oficial. De este modo, el objetivo del clickbait, como un anzuelo para captar la atención de las personas, ya se cumplió. 
En forma cronológica, las notas informativas tratan de mantener la tendencia alrededor de Paolo Guerrero, de manera que siempre se tenga una noticia sobre el tema que lo vincula a una posible contratación profesional, aunque periodísticamente estas publicaciones respondan más a presunciones que a notas directas.

La recurrencia del clickbait y técnicas sensacionalistas origina una nueva estructura de lenguaje, donde el titular y la bajada son información verídica y, el desglose, que vendría a ser el sustento de la parte inicial, termina siendo una especulación o información contraria a lo que se afirmó en el principio. Este modelo de desinformación conlleva una nueva "normalización", la cual puede ser utilizada por los diarios deportivos.

Esta "normalización" del clickbait como estrategia del sensacionalismo pasaría a ser una realidad absoluta, la cual, a pesar de su concepción negativa, podría ser utilizada con un fundamento válido comercial. La repetición o recurrencia de esta estrategia del sensacionalismo puede, incluso, concretar una idea de norma en las redacciones periodísticas. El hecho de que el uso del clickbait sea tomado como un parámetro verosímil, indicaría que su uso estaría restringiendo el objetivo del periodismo riguroso.

Podría generarse, entonces, la siguiente pregunta: ¿El uso del clickbait sigue siendo periodismo?

Es importante indicar que una de las notas informativas analizadas fue eliminada de la web de Depor.com. Se trata de la nota 3, donde se afirma rotundamente lo siguiente: "Paolo Guerrero ya tiene fecha de llegada a Boca Juniors y develan cuánto ganará como 'Xeneize"”. Este accionar genera una pregunta tan simple del por qué se borró si, supuestamente, toda la información es verídica. Justamente ahí entra el tema de la especulación.

\section{Fuentes consultadas}

Alabarces, P. (2018). El fútbol en América Latina. El Colegio de México.

Arango, G. (2005). Siglo XXI: hacia una nueva deontología del periodismo deportivo. Palabra clave, 8(13), 139-151. https://palabraclave. unisabana.edu.co/index.php/palabraclave/article/view/1465/1633 
Barja, L. (2016). El perfil del nuevo periodista digital peruano en los procesos de convergencia de plataformas. Casos El Comercio, RPP Noticias y Epensa [Tesis de licenciatura]. Universidad Nacional Mayor de San Marcos. https://cybertesis.unmsm.edu.pe/handle/20.500.12672/4830

Bazaco, A., Redondo, M., \& Sánchez-García, P. (2019). El clickbait como estrategia del periodismo viral: concepto y metodología. Revista Latina de Comunicación Social, (74), 94-115. http://www.revistalatinacs. org/074paper/1323/06es.html

Briggs, A., \& Burke, P. (2002). De Gutenberg a Internet: una historia social de los medios de comunicación. Santillana Ediciones Generales.

Carrión, F., \& Pérez, R. (2006). Área de candela. Fútbol y literatura. Flacso.

Castillo, R. (2013). Criterios que rigen la producción de noticias sobre los fichajes profesionales en el Perú: el caso del diario Depor [Tesis de licenciatura]. Pontificia Universidad Católica del Perú. http://repositorio.pucp.edu.pe/index/handle/123456789/150822

Clarín. (21 de diciembre de 2018). Nuevas palabras: Qué significa y de dónde viene la frase: "Vender humo". Clarín. https://www.clarin.com/sociedad/significa-viene-frase-vender-humo_0_oTQXFImD9.html

Domínguez, J. (2009). Ensayo sobre la cuádruple espectacularidad del periodismo deportivo. Razón y Palabra, (69). https://www.redalyc.org/ pdf/1995/199520330048.pdf

Galindo, J. (2009). Comunicología y fútbol: La vida social, el deporte y el espectáculo desde una perspectiva constructivista. Razón y Palabra, (69), 13-27. https://www.researchgate.net/publication/40901799_Comunicologia_y_futbol_La_vida_social_el_deporte_y_el_espectaculo_ desde_una_perspectiva_constructivista

Gallur, S., García, B., \& López, X. (2017). El uso del clickbait en cibermedios de 28 países de la Unión Europea. Revista Latina de Comunicación Social, (72), 1.261-1.277. https://doi.org/ doi: 10.4185/RLCS-2017-1218

Gargurevich, J. (1999). Lo real/exagerado: la prensa sensacionalista en el Perú, de las relaciones a los diarios chicha [Tesis de maestría]. Pontificia Universidad Católica del Perú. http://tesis.pucp.edu.pe/repositorio/ handle/20.500.12404/4534 
Gómez, J. (2013). Análisis ético de la prensa deportiva escrita en Cataluña, en el empleo de técnicas sensacionalistas. Razón y Palabra, 17(4), 256-280. https://www.revistarazonypalabra.org/index.php/ryp/article/view/429

Hinojosa, G. (2014). Periodismo y propaganda en el Perú. Una relación compleja durante los procesos electorales. Correspondencias \& Análisis, (4), 259-281. https://doi.org/10.24265/cian.2014.n4.13

Learreta, J. (2017). Clickbait, Redes Sociales y Medios de Comunicación. Análisis del uso del clickbait y las distintas estrategias de marketing digital en las redes sociales de los principales medios de comunicación españoles [Tesis de pregrado]. Universitat Jaume I. http://repositori.uji. es/xmlui/handle/10234/172817

Luzón, V. (2000). Periodista digital: de MacLuhan a Negroponte. Revista Latina de Comunicación Social, 3(34). https://www.redalyc.org/ pdf/819/81933408.pdf

Mellado, C., \& Scherman, A. (2018). La performance periodística en la cobertura deportiva: un estudio comparado de televisión, radio, prensa impresa y medios online en Chile. Palabra Clave, 3(22), 1-27. https:// doi.org/10.5294/pacla.2019.22.3.8

Mendoza, M. (2017). El rostro de los diarios digitales en el Perú. Fondo Editorial Universidad de Lima.

Nívea, R. (1994). Elementos para una teoría del periodismo sensacionalista. Comunicación y Sociedad, 21, 139-157. https://www.academia. edu/35011435/Elementos_para_una_teor\%C3\%ADa_del_periodismo_ sensacionalista_1994_?auto=download

Palau-Sampio, D. (2016). Metamorfosis de la prensa de referencia en el contexto digital: clickbait y estrategias de tabloide en Elpais.com. Communication \& Society, (29), 63-79. https://doi.org/10.15581/003.29.2.63-79

Pulgar, J. (2018). De golpes y goles. Universidad Peruana de Ciencias Aplicadas.

Pujadas, X. \& Santacana, C. (2012). Prensa, deporte y cultura de masas. El papel del periodismo especializado en la expansión social del deporte en Cataluña hasta la guerra civil (1890-1936). Historia y comunicación social, (17), 141-157. https://doi.org/10.5209/rev_HICS.2012. v17.40603 
Real Academia Española. (s.f.). Vendehúmos. Diccionario de la lengua española. https://dle.rae.es/vendeh\%C3\%BAmos

Redondo, M. (2013). El sensacionalismo y su penetración en la prensa española de calidad. El "caso McCann" en El País, El Mundo y ABC. Estudios sobre el mensaje periodístico, 19(1), 235253. https://doi. org/10.5209/rev_ESMP.2013.v19.n1.42519

Regalado, D. (2006). Expresiones emotivas del discurso periodístico deportivo. Cuadernos de lingüistica hispánica, (7), 85-94. https://www.redalyc.org/pdf/3222/322230192008.pdf

Rojas, J. (2012). La futbolización de la información deportiva. Comunicación \& Cultura, (13), 77-95. https://www.researchgate.net/publication/288669462_La_futbolizacion_de_la_informacion_deportiva

Rojo, L. (2019). Del papel al clickbait. El caso de los periódicos online regionales del Grupo Vocento [Tesis de Licenciatura]. Universidad de Valladolid. http://uvadoc.uva.es/handle/10324/39718

Sánchez, L. (2007). Evolución del periodismo digital peruano. Análisis de los casos: rpp.com, elcomercioperu.com, panamericana.com y terra.com 1995-2005 [Tesis de licenciatura]. Universidad Peruana de Ciencias Aplicadas. https://repositorioacademico.upc.edu.pe/handle/10757/273393

Vargas, R. (2018). El sensacionalismo como discurso periodístico de las portadas de diarios deportivos: Caso Depor en la cobertura de la selección durante el mundial [Tesis de licenciatura]. Universidad Peruana de Ciencias Aplicadas. https://repositorioacademico.upc.edu.pe/bitstream/ handle/10757/625877/VARGAS_LR.pdf?sequence=3\&amp\%3BisAllowed $=\mathrm{y}$

Vázquez, M. (1980). Historia y comunicación social. Alianza Editorial

Yezers'ka, L. (2008). Tendencias de los diarios digitales en Perú. Revista Latina de Comunicación Social, 11(63), 71-82. https://www.redalyc.org/ pdf/819/81912006007.pdf

Yezers'ka, L., \& Zeta, R. (2016). Veinte años de medios digitales en el Perú (1995-2015). https://www.researchgate.net/publication/306441049_ Veinte_anos_de_medios_digitales_en_el_Peru_1995-2015 